\title{
MISS JULIE: A PSYCHOANALYTIC STUDY
}

\author{
Sonali Jain \\ University of Delhi, India
}

\begin{abstract}
Sigmund Freud theorized that 'the hero of the tragedy must suffer...to bear the burden of tragic guilt...(that) lay in rebellion against some divine or human authority.' August Strindberg, the Swedish poet, playwright, author and visual artist, like Shakespeare before him, portrayed insanity as the ultimate of tragic conflict. In this paper I seek to explore and reiterate the dynamics of human relationships that are as relevant today as they were in Strindberg's time. I propose to examine Strindberg's Miss Julie, a play set in nineteenth century Sweden, through a psychoanalytic lens. The play deals with bold themes of class and sexual identity politics. Notwithstanding the progress made in breaking down gender barriers, the inequalities inherent in a patriarchal system persist in modern society. Miss Julie highlights these imbalances. My analysis of the play deals with issues of culture and psyche, and draws on Freud, Melanie Klein, Lacan, Luce Irigaray and other contemporary feminists. Miss Julie is a discourse on hysteria, which is still pivotal to psychoanalysis. Prominent philosophers like Hegel and the psychoanalyst Jacques Lacan have written about the dialectic of the master and the slave - a relationship that is characterized by dependence, demand and cruelty. The history of human civilization shows beyond any doubt that there is an intimate connection between cruelty and the sexual instinct. An analysis of the text is carried out using the sado-masochistic dynamic as well the slave-master discourse. I argue that Miss Julie subverts the slave-master relationship. The struggle for dominance and power is closely linked with the theme of sexuality in the unconscious. To quote the English actor and director Alan Rickman, 'Watching or working on the plays of Strindberg is like seeing the skin, flesh and bones of life separated from each other. Challenging and timeless.'
\end{abstract}

Key words: psychoanalysis, slave-master, sado-masochism, narcissism, hysteria, culture, psyche 


\section{Introduction}

Sigmund Freud theorized that 'The Hero of tragedy must suffer...to bear the burden of what was known as 'tragic guilt'.. (that) lay in rebellion against some divine or human authority.' (Freud, 1950, p. 156)

August Strindberg, the Swedish poet, playwright, author and visual artist, like Shakespeare before him, portrayed insanity as the ultimate of tragic conflict. Strindberg is a trailblazer as a playwright where he submits incisive personal experience into his naturalistic and later, his expressionist plays, as well as in his novel Inferno. Not only does he not limit himself to a nineteenth century ideal of an artist, but his work transcends time as he portrays human existence.

'Filthy..., 'a heap of ordure..., 'debauched...', 'will surely nowhere find an audience that could bear to see it...', 'totally repellent...', 'repulsive...' This is how critics responded to Froken Julie (Miss Julie) when it was published on 23 November 1888. In this paper I seek to explore and reiterate the dynamics of human relationships that are as relevant in contemporary times as they were in Strindberg's era. I propose to examine Strindberg's Miss Julie through a psychoanalytic lens.

\section{The life and times of Strindberg}

August Strindberg was born in 1849 in Stockholm, with nine siblings, and believed that he was unwanted. He experienced grave deprivation and exclusion in his family, imbibed his father's shame and fears, and also the squalid subservience of his mother. As a result, he became oversensitive, deeply craving for his parents' unconditional love.

He married three times and got engaged at the age of sixty to a young actress called Fanny Faulkner. Shortly before his death, he was asked in a questionnaire which qualities he valued most highly in a woman. His answer was 'motherliness'. Several of his plays drew upon the problems of his marriages and reflected his constant search in self analysis.

To follow Strindberg's life, it is imperative to look closely at his marriage with Siri Von Essen, Baroness Wrangel, to whose house Strindberg was taken by a friend because the Wrangels were keenly interested in theatre and wished to meet him. Coincidentally he found himself in a house where he had spent much of his youth, where he had experienced the loss of his mother and his father's remarriage. Strindberg did not see Siri von Essen as the Baroness Wrangel but as Virgin Mother. 
He found the idealized parental figures, a love object with whom he could identify and whose admiration he sought. He married Siri and the marriage rekindled intense pre-oedipal and oedipal conflicts concerning longing for reunion with the mother, distrust of the parental objects, rebelliousness against the authority of the father, and insecurities over his sexual identity.

After thirteen troubled years, his marriage to Siri von Essen ended in 1891. Strindberg moved to Berlin after having divorced Siri, where he met the Austrian journalist Frida Uhl whom he married next. This marriage lasted two years. Haunted by guilt about deserting his children and attacked by his critics, Strindberg became possessed of a persecution mania. Between the years 1892 and 1897 he experienced several psychotic episodes. He longed for a reunion with the maternal, at the same suffering from an extreme primal guilt.

\section{Setting of the play Miss Julie}

The play is set on Midsummer's Eve, a festival of pagan origin in Northern Europe, which has particular charm of its own when the sun does not set. It is a night on which with the scents and sounds of the intense Northern summer drive people mad. In Miss Julie the pagan fertility ritual is in marked contrast to the sterility of the world of Miss Julie, where she is an unwanted child, where the bitch is shot for running with the gatekeeper's dog, a metaphor for keeping class conflict and hierarchy in place. It is interesting to see how the play works in terms of space. The kitchen forms an important space, for that is where all activity takes place in the play. The kitchen is the domain of the working classes. Also, it is a place where another kind of appetite is satisfied. In the play, a pantomime is set as if 'the actress was really alone in the kitchen'.

There are only three characters in the text that are present on stage. Miss Julie is the Count's daughter and the mistress of the house, Jean the valet and Christine the cook. It is also a world where the only progenitor, Miss Julie's father, is absent. The dancing peasants punctuate the action in the play, reinforcing the imminent danger in Miss Julie's act of indiscretion. We are not given a glimpse of the bedroom - the sexual centre. We are given a frolicking chorus of villagers and farmers instead. It is interesting to note that in drawing the curtain on the bedroom, the playwright plays upon the spectator's desire to see the sexual act, which unconsciously carries the excitement/burden of witnessing the primal scene.

The peasants sing about 'two women in the wood'. Earlier, there is a hint of Miss Julie 'with her lady friend'. The song hints at Miss Julie's unconscious wish to unite with the primary object, i.e., her mother in her mind. She goes through the 
seduction and plays out her sexual wishes almost with a childlike innocence, as if acknowledging sexual wishes even in the mind would be dirty and lead to disapproval from the Mother. At the same time there is an unconscious wish to be the 'man to the mother' (Bollas 2000).

\section{Culture and Psyche}

Miss Julie is a discourse on hysteria, which is still pivotal to psychoanalysis. My analysis of the play deals with issues of culture and psyche, and draws on Sigmund Freud, Melanie Klein, Jaques Lacan, Luce Irigaray and other contemporary thinkers. I also take up the dialectic of the master and the slave - a relationship that is characterized by dependence, demand and cruelty. The history of human civilization shows beyond any doubt that there is an intimate connection between cruelty and the sexual instinct. An analysis of the text is carried out using the sado-masochistic dynamic as well the slave-master discourse. I argue that Miss Julie subverts the slave-master relationship. The struggle for dominance and power is closely linked with the theme of sexuality in the unconscious.

The play deals with bold themes of class and sexual identity politics. Notwithstanding the progress made in breaking down gender barriers, the inequalities inherent in a patriarchal system persist in modern society. Miss Julie highlights these imbalances.

\section{Slave-Master discourse}

Miss Julie takes up the theme of the Darwinian battle between the sexes, and a love hate bond. It is a play about the slave master discourse. The slave, because of his subjectivity and loss, has some chance of reflecting and recognizing his own desire: the master has far less chance of recognizing his desire because he pressures the slave to recognize his 'demand' for enjoyment. For Lacan the slave master relation is universal, one in which we have invested either as slaves in some voluntary sense or as masters. The idea and practice of being a slave is always entangled with the idea of being a master and vice versa.

For a psychoanalytic reflection the text it is important that one look at what this master slave discourse actually entails. In the play, Miss Julie is the mistress while Jean is the slave. The text subverts the master slave relationship through its economical handling of characters and their complex relationships with each other. The struggle for dominance and power is closely linked with the theme of sexuality: seeking and bestowing sexual favours. At many levels, particularly at the sexual 
level, Jean acts as the master, subjugating Miss Julie, while she acts out the role of a slave.

The relationship between Christine and Jean is an equal one; interestingly, Christine is aware of Jean's reaction to Miss Julie but in a typical patriarchal manner, is willing to tolerate Jean's philandering as long as he returns to her in the end. The play begins with a conversation that establishes the complicity between Jean and Christine. Jean and Christine are immersed in half amorous banter with frequent references to the absence of Miss Julie and her wild sexuality almost like her bitch in heat. Ironically Miss Julie's bitch is called Diana and in Roman mythology, Diana is the Goddess of Virgins. Christine also mentions that Miss Julie is menstruating (p. 3) .

Jean: Miss Julie is wild tonight, completely wild.

Christine: He's back, is he?

Jean introduces Miss Julie as a woman who wishes to dominate men, subjecting them to her sadistic will. Her fiancé has walked out on her, because of her wish to 'train' him, her urge to crack the whip. However, once the engagement is broken, she is too ashamed to show herself in public and seeks confinement in the home with the servants in disgrace. The whip is a phallic symbol that signifies Miss Julie's masculinity and identity as a master while the references to her bodily functions - her sexual urges and her menstruation - establish her vulnerability as a sexual being, and as a woman.

Miss Julie walks into the kitchen and flirtatiously asks Jean for a schottische with her (p. 6). Julie's manner is coquettish, intent on teasing Jean but not expressing a direct sexual wish. Jean too engages with her in a mock romantic fashion speaking in French and setting a sentimental scene of seduction, even kissing her foot. Miss Julie is delighted by Jean's performance and tells him that he should have been an actor. She acts innocent when points out the dangers of gossip, and even jeers at him. Jean insists that this flirtation ought to stop for fear of discovery by the Count-Father.

As the sequence of events unfolds, Jean and Julie express their desires and their fantasies to each other. Miss Julie and Jean start playing out the slave master dialectic. Miss Julie tries to wake Christine because she envies Jean's fiancé. Christine's name being close to the word 'Christian' has its own connotations. Christine is the punitive, disapproving mother in Miss Julie's unconscious. She babbles about the authority of the Father in her sleep i.e., the Count's boots which also stand for his class, power and sexuality. With Christine sleeping, Miss Julie can be even more brazen in expressing her wish. Jean half protests by calling her 'Miss Julie'. Strind- 
berg constantly keeps us reminded of her social class and also her virginity, her innocence about sexuality'. Jean tells Miss Julie that he must polish the Count's boots, indirectly asserting his consciousness about his social class.

According to Luce Irigaray, 'red blood' signifies a tangible relationship between men and women, a matriarchal role for women and indeed menstruation is a signifier of womanhood. To refer to Luce Irigaray's 'When the goods get together' in This Sex Which is Not One (1985), it is significant to note the rejection of phallocentrism of Freud and Lacan, despite having been Lacan's student. Irigaray employs Marxist and Psychoanalytic concepts and vocabulary, calls women 'goods' to be exchanged between male members of society: brother, father, husband... and thus, there is no interaction between the female sex. Irigaray strongly emphasizes the bonds of womanhood. She critiques Freud rather strongly for regarding female sexuality as 'virility complex' and accuses him of transferring his own bias.

\section{Trappings of Narcissism}

Jean's story about the outhouse transforms Miss Julie into a narcissistic listener. She is fascinated by the narrative, which has her as the heroine and perhaps this is the best moment of narcissistic satisfaction that Miss Julie manages in the course of the play. Jean's reminiscence has all the trappings of a fairy tale: the servant who falls in love with his mistress at first sight, the seven brothers and sisters, the forbidden garden with apple trees, the bed of alder leaves cleverly puts Miss Julie under his spell. The fantasy does reveal Jean's fervent desire to live a life of the rich. Money is what which will give him a sense of omnipotence.

The story is not entirely false as it contains the seed of Jean's wish to transcend his social class. In the unconscious, it also means getting more love from the Father, psychoanalytically: the Count. Jean's story is ironic, his description of the filthy outhouse (p.16):

I had never been inside the manor house, never seen anything except the church - but this was more beautiful.

Jean's comparison degrades churches and castles just as effectively as it mocks the foul outhouse. Positions in space reflect positions in class and gender. Jean's lies in filth, while Miss Julie walks on the rose terrace. He is not only the figure humiliated by his masters but a servant who can see their undersides. 


\section{Dreams as signifiers}

Jean's and Miss Julie's dreams are also important signifiers. Miss Julie relates a recurrent dream (p. 12) :

... I'm on top of a pillar. I'm sitting there, and I see no possible way of getting down. I feel dizzy when I look down but I know I must get down. I haven't got the courage to throw myself. I can't hold on. I long to be able to just fall but I don't fall. I know I won't have any peace until I'm down, no rest until I'm down, down to the ground. I also know that once I am down I'll want the ground to open and for me to sink, sink...

Jean's dream (p. 13) runs like this;

I dream that I am lying underneath a tall tree in a dark forest. I want to get up up to the top and look around me across the bright landscape where the sun shines. I want to plunder the bird's nest up there with the golden eggs. I climb and climb but the trunk is so thick and slippery and it's so far to the first branch. I know that if I could only reach that first branch I could climb up to the top step by step. I haven't reached it yet but I will reach it, well, in my dreams.

At the manifest level, the dream reflects Miss Julie's ambiguous attitude towards her social class. It isolates her and puts her up on a pillar, far from the ground though it gives her visibility and power. However, at the immanent level, the dream reflects Miss Julie's ardent wish to return to the mother's womb, to fuse with the primary object i.e., the mother. One thinks of the ground as 'mother earth', an all embracing, and loving, benevolent mother. The dream also hints at a possibility that Miss Julie is embarrassed about her sexual conduct and sexual desires and feels a strong sense of shame, enough to sink into the ground/ experiencing a strong death wish. Guilt and shame shall be taken up later in the paper.

Jean's dream is also about his wishes. He wishes for an experience of fulfillment, which will make everything seem bright. Once again at the manifest level, the dream signifies Jean's desire to transcend his social class and plunder a high class by sexually possessing Miss Julie. However, at the immanent level they are homosexual wishes, if psychoanalytically analysed. Images of a tall tree, the thick and smooth trunk are sexual images. He 'desires' the Father, the source of power and class. In Lacanian terms, Miss Julie is only his object of 'demand'. 


\section{Miss Julie's Trauma}

After the seduction of Miss Julie by Jean, she is at Jean's mercy. She pleads with him to call her by her name 'Julie', trying to establish equality between them. She talks about her trauma after the seduction in her anxiety not to be punished by her family, and society at large. In the unconscious, she has dared to express desire and has seduced the Father. Jean says that it is impossible to continue to stay at the manor. $\mathrm{He}$ fantasises about travelling to Italy and setting up a hotel there (pp. 20-21):

Jean (enters agitated): There you see. And you heard. Do you think it's possible to stay here now?

Miss Julie: No. I don't think so. But what can we do?

Jean: Escape from here.

Miss Julie: Escape yes, but where to?

Jean: To Switzerland, the Italian lakes - have you ever been there?

Miss Julie: No. is it beautiful there?

Jean: Eternal summer: laurels, orange trees, ...

Miss Julie: But what do we do there?

Jean: I'll set up a hotel. First-class service for first class customers.

Miss Julie: A hotel?

Jean: That's living, believe me: new faces all the time, ... while the money keeps rolling in. That's living.

Miss Julie: Yes, for you, but what about me?

Jean: You will be the mistress of the house; the jewel in the crown... I'll fiddle the bills and you'll cover up with your sweetest smile....

Miss Julie: That's all very well but Jean - you must give me courage. Say that you love me. Hold me.

Jean: I want to - but I daren't. Not in this house any more. I love you Miss Julie, I do ... Miss Julie: Julie - say Julie. There are no barriers between us any more, Say Julie.

When Miss Julie pleads that she has no money to elope with Jean, he is completely cruel and unsympathetic, and says that his story about the rose terrace was entirely fabricated. Miss Julie is traumatized.

A trauma is an important impossibility and refers to an experience in a person's life that he has not been able to sufficiently symbolize or to put into language. In his theory of repression Freud says that if somebody were the victim of trauma that they have repressed, some aspect of their repressed experience would return. When Miss Julie is faced with Jean's accusation that she has acted like a 'beast and a 'whore', both extremely patriarchal terms, she is prostrate. 
Miss Julie's submission to Jean reflects Strindberg's notions of evolution. $\mathrm{He}$ suggests that Miss Julie must fall to Jean, because he was convinced that women are inferior to men. As Strindberg has noted in the Preface to the play Miss Julie he has 'added a little evolutionary history [to the play] by making the weaker steal and repeat the words of the stronger'.

\section{Hysteria}

Strindberg's anger is apparent in Miss Julie's continued humiliation. Her mother's anti male ideas are portrayed as ridiculous and her duplicity as a familiar tale. Jean thinks that Miss Julie is 'sick', a diagnosis we are meant to agree with. This scene blames Miss Julie's illness on her family history. Strindberg was interested in psychology and depended heavily on it in delineating his characters in his naturalistic plays. Miss Julie and the Countess are models of the hysteric as popularly conceived of in the nineteenth century. Symptoms of hysteria are to keeping wanting and craving, also waiting. When we think of hysteria we think of people, who are troubled by their body's sexual demands and repress sexual ideas; who are over identified with the other, who express themselves in a theatrical manner: who daydream existence rather than engage it.

Miss Julie is only interested in those people who do not reciprocate her feelings, thereby always experiencing pain. There was also the disease which the nineteenth century referred to as 'nostalgia.' 'Hysterics suffer from reminiscences. ...wanting is central to a Freudian theory of hysteria' (Mitchell 1999, p. 25).

Freud first tackled hysteria in the 1880's. Strindberg was influenced by the French psychiatrist Charcot who was investigating hysterical affliction's via hypnosis. Theories of hysteria in the nineteenth century were based on sexual disturbances. It was theorized primarily by both Freud and Charcot that women became hysterics when they repressed their sexual desires.

The character of Miss Julie is etched as one of a 'hysteric': a sensitive and hungry little girl who wanted and craved for love, but did not get unconditional maternal care in infancy. There is disappointment with her mother who failed to make her feel safe, sated and prized. As she approached the oedipal phase, where she began to experience desire for the father, she did so by devaluing her primary object - her mother - and turned her intense love towards her father. Her father was perceived by her as extremely exciting. She could not compete with her mother in trying to win the father and hence was trapped in a dilemma. As a result of this fixation, Miss Julie finds men strong and exciting and moves away from homosexual wishes (which are perhaps there in her unconscious) to hyper-sexualised, hetero- 
sexual love and desire. She sees women, herself included as weak and insignificant. Miss Julie manipulates her sexuality and her wiles and uses sex defensively because she is too afraid of the abuse of power by men. The Countess is also portrayed as hysteric. To make up for the lack of the phallus, i.e., her lack of power - she was a commoner by birth and from a very simple background - she raised Miss Julie as a boy (note the irony-'Miss') and taught her to hate men.

... She had an aversion to marriage. So when she met my father and he proposed to her, she told him she couldn't be his wife but he could be her lover. First, my father resisted because he wanted the woman he loved to be respected the same way he was. But he adored her, so he gave in and accepted her condition....my parents were living in sin, so they were rejected...then I came into the world against my mother's wishes as far as I can make out. I was allowed to run wild, I was taught everything boys are taught. I was to be the living proof that a woman is as good as a man. I wore boy's clothes, learned how to groom, how to harness, how to shoot, even how to slaughter. That was horrible. (p. 28)

Miss Julie's actual act of intercourse with Jean also seems like a dissociated, hysterical experience in the play. She does not own up to any sexual desires despite having being coquettish. Here one notices splitting on the part of Miss Julie - the virtuous helpless mistress on the one hand and the seductress on the other hand. Both parts are kept away from each other. For her there must be love because from her mother she has imbibed that sex is dirty, and there is guilt associated with it.

The play uses the metaphor of filth and dirt both signifying sexuality in the unconscious. Jean recounts that the Countess was 'most at home in the kitchen and the cowsheds but a one horse carriage wasn't elegant enough for her.' Miss Julie has dirt under her painted nails. Also, when she comes down dressed to travel, Jean points out that her face is dirty. He tells Christine how she went around with 'dirty cuffs. Dirt stands for the unbridled sexuality of women in which they are not conscious of class barriers.

\section{Sado-masochistic dyad}

In the beginning Miss Julie tries to assert herself as the mistress of the house and tries to seduce Jean. If one looks closely at Miss Julie's unconscious patterns, there are processes of regression in her which must be acted out again and again via her sexuality. Once her weakness and her sexually uninhibited nature are brought to the fore, Jean denies her, torments her and has power over her. His element of aggression is extremely high and Jean and Miss Julie get embroiled in a sado -mas- 
ochistic dyad.

It is important to understand why Miss Julie is masochistic. The term masochism applies to any passive attitude towards sexual life and towards the sexual object. In its extreme instance, satisfaction becomes conditional upon suffering physical or mental pain at the hands of the sexual object. It is not certain whether masochism is a primary phenomenon or whether it gets sparked off by sadistic pleasure turned inwards towards the self. It can often be shown that masochism is nothing more than an extension of sadism turned round upon the subject's own self who, thus, to begin with, takes the place of the sexual object.

Miss Julie's trauma is her oedipal wish which she tries to actualize throughout her life. In his theory on repression Freud says that if somebody were the victim of a trauma that they had repressed, some aspect of their repressed experience would always return. Masochistically imploring her servant to at once punish her for passion and help her out at the same time. She hates and desires Jean at the same time. Through Jean, Miss Julie wishes to touch upon her own anger at the self. For her, as stated earlier, passion becomes punishment socially and psychologically.

Miss Julie's masochism, i.e., her pathetically allowing Jean to hurt her, and dominate her, is at a deeper level, her own anger directed at herself. It is her sense of shame and rejection more than the impending humiliation which Miss Julie anticipates that makes accept punishment at the hands of Jean. Miss Julie allows Jean to treat her badly because deep down she wants to punish herself for desiring Jean who is not her equal. This helps her deal with her intense guilt and she feels closer to the father structures in her mind.

I would like to quote from Freud's paper 'A Child is Being Beaten' (1919). Freud elaborates how fantasies and self punishment are actually a desire to feel most loved, special and wanted by one's father. Sigmund Freud maintains that every pain contains in itself the possibility of a feeling of sexual pleasure.

According to Freud:

... the first phase of beating phantasies among girls, then, must belong to a very early period of childhood. The child being beaten is never the one producing the phantasy, but is invariably another child, most often a brother or a sister if there is any. This first phase of the beating phantasy is therefore completely represented by the phrase: 'My father is beating the child'. I am betraying a great deal of what is to be brought forward later when instead of this I say 'My father is beating the child whom I hate.'

Profound transformations have taken place between this first phase and the next. It is true that the person beating remains the same (that is, the father); but the child who is 
beaten has been changed into another one and is now invariably the child producing the phantasy. The phantasy is accompanied by a high degree of pleasure. Now, therefore the wording runs:

\section{'I am being beaten by my father.'}

Freud adds that:

... if the child in question is a younger brother or sister, it is despised and hated: yet it attracts to itself the share of affection, and this is a spectacle the sight of which cannot be avoided. One soon learns that being beaten, even if it does not hurt very much, signifies a deprivation of love and a humiliation. The idea of the father beating this hateful child is therefore an agreeable one. It means 'My father does not love this other child, he loves only me.'

The pleasure attaching to this phantasy is both sadistic and masochistic. This infantile perversion persists throughout in both Miss Julie as well as in Jean.

The play is not time bound. It is a remarkable encounter of two people who love and hate themselves and each other in such and intense crucible of event and emotion. One is never quite sure of the roles of slave/ master. Indeed there is pleasure in Miss Julie's humiliation but one gets completely enmeshed in this sado-masochistic dyad.

\section{Shame and Guilt}

The theme of guilt pervades the play. Throughout the play, Miss Julie is aware of the presence of Christine and her 'rightful claim over Jean'. The beheading of John the Baptist is a symbolic castration. Guilt is an important concept in psychoanalysis, which Miss Julie experiences rather intensely. According to the psychoanalyst Melanie Klein, the infant's world is threatened from the beginning by intolerable anxieties, whose source she believed to be the infant's own death instinct. These 'persecutory' anxieties, which are felt in the infant's own bodily needs as well as from the external frustrations to those needs, are overwhelming to the infant, and in order to combat them, the infant resorts to defenses. Through primitive defenses-projection, denial, splitting, withdrawal, and 'omnipotent control' of these objects-the infant puts threatening, 'bad' objects, outside herself and into the external world; simultaneously, she preserves the 'good' objects, both within herself and externally, by splitting them off from their malevolent counterparts (Klein 1986).

Perhaps the most fundamental of these processes were projection and introjection, which describe the infant's first, primitive attempts to differentiate himself 
from the world, inside from outside, self from other, based on the prototype of oral incorporation (and spitting out) and the infant's relation to his first, nurturing/frustrating object- the mother's breast. The first objects were not the mature, 'whole' objects of Oedipal development, but primitive 'part' objects whose existence for the infant was determined solely by its function in the infant's world.

Using the Kleinian model, Miss Julie has in course of maturation, 'bad' and 'good' objects, and that through processes of progressive internalization, these fragmentary objects were taken into the self, and became forerunners of the superego. Klein emphasized that this process (of introjection, projection, and re-introjection) was continuous and cyclical, leading to increasing synthesis as Miss Julie gradually attained greater degrees of reality testing, differentiation, and control over her own psyche.

Klein (1986) divided pre-Oedipal development into the "paranoid/schizoid" and "depressive" positions. She located the paranoid/schizoid position in the first months of an infant's life, a time in which the infant was in helpless thrall both to the outside world and to his own instincts. Deprivation, the experience of need, and frustration, even though emanating from the infant's own body, were perceived during this phase as persecutory, and the infant responded by putting them outside of himself, 'projecting' or throwing them away.

The early objects—beginning with the breast-were experienced alternately as 'good' or 'bad' according to whether they were perceived as nurturing or destructive; and again partly on the model of the breast, the infant took in (introjected) or dispelled (projected) them according to their relative safety or danger.

In this way, Miss Julie took in and preserved those feelings in the external world that were felt as 'good,' while expelling from herself those destructive feelings directed 'into' the object that threatened the relation with the object. In the depressive position Miss Julie is able to bridge the gap between 'good' and 'bad' objects, between her own experiences of love and hate, which created them. Her awareness gradually grows to encompass the object world outside herself. She becomes aware of her own destructive impulses and, fearing the loss of Jean's love, attempts to inhibit them, to preserve, protect, and even resurrect the object that she continually destroyed in unconscious fantasy. Her anxious awareness of her aggression toward the object/mother (which Klein called guilt) takes the better of her, and subsequent efforts to contain her own anxieties by curtailing these impulses (efforts Klein termed reparations), are unable to lead Julie to an increasing tolerance for ambivalence. 
In a pantomime Jean does some calculations in a notebook as Christine enters. Christine reminds Jean that he promised to join her at church that morning. The sermon is on the beheading of John the Baptist. Jean also confesses to Christine that he and Miss Julie have been intimate. Christine expresses disbelief that Miss Julie who has been so proud with men, even having her dog shot for copulating with a mongrel, could do a thing like that.

The sun rises, marking the end of Midsummer Eve. Miss Julie fantasizes about men's annihilation and the fantasy reveals her most violent, desperate, punitive and revengeful self. This fantasy is set off by the scene of the decapitation of the greenfinch, an act that links up with Christine's mention of the execution of Saint John the Baptist, the famous Biblical allegory. The decapitation is a symbolic castration in psychoanalytic thought. Miss Julie implores Jean to kill her as well, identifying completely with the greenfinch.

\section{The Father}

It is interesting to note that both the figures of the mother and father are absent from the heart of action that is the stage. There is a detailed and deliberate set of stage directions, which also introduce the most important signifier in the play -the Count's boots. The boots signify not only sexuality, but also the absence and the presence of the Count/ Father, simultaneously.

These innumerable power rehearsals between Miss Julie and Jean are reduced to a joint submission to the Count. The Count-unseen and unheard is a supreme magical authority. It expects Jean's return to servitude/slave and Miss Julie's extinction for transgressing her limits. She is hypnotized and proceeds towards death holding a razor in her hands.

\section{Summary and Conclusion}

Strindberg wrote with unprecedented candour about sex. In Miss Julie he has excelled in depicting people driven by love, envy, jealousy and hatred into a nightmarish state of madness. In Miss Julie, he cut the classical three-act construction to a single act, focused on a triangular relationship in which a whole spectrum of suicidal and homicidal emotions is depicted.

There are several opinions on the theme as well as on the structure of the play. To summarise them would be as follows: Alice Templeton (1990) calls Miss Julie a naturalistic tragedy. She discusses the misogyny of Strindberg in the context 
of the preface to the play. John Greenway (1968) deals with the important theme of hypnotic suggestion and situates the play in the context of the advent of science in the nineteenth century. Sprinchorn (1968) also analyses Strindberg's treatment of naturalism and tragedy in Miss Julie.

In conclusion I would like to argue that August Strindberg is not a misogynist. There is colour in his creative excitement, he experienced anger with colour, and called it the strongest of all spiritual emotions. Strindberg enjoyed the whole package of madness. As Helen Cooper observes, 'Strindberg the Misogynist actually took women very seriously' (Strindberg 1992/1888, p. x).

As Strindberg himself observes, ‘... and if I had to define my present stand point it would be: Atheist, Christ- hater, Anarchist...P.S. Woman being small and foolish and therefore evil, should be suppressed like barbarians and thieves, she is useful only as an ovary and womb, best of all as a cunt.' (p. vii) In the same breath we also experience his 'misogyny' when he says... 'Actually, my misogyny is purely theoretical, and I can't live a day without deluding myself that I warm my soul in the glow of their unconscious vegetable existence.

He impatiently rejects nineteenth-century notions of fixed dramatic characters according to their types. 'My hypothesis', his mentor Nietzsche once wrote, 'is the subject as multiplicity'. Strindberg agrees: 'Since they are modern characters, living in an age of transition, more urgently hysterical at any rate than the age which preceded it, I have drawn my people as split and vacillating, a mixture of the old and new'. Again: 'My characters are conglomerations of past and present stages of civilization, bits from books and newspapers, scraps of humanity, rags and tatters of fine clothing patched together as is the human soul.'

His preface to Miss Julie is the classic declaration of early modernism that human nature is mysterious, contradictory, ambivalent and indecisive. It is possible, for example. To experience both feelings of hatred and of lust towards the same person, as Strindberg himself did with all his wives and lovers. The self as an arena of conflicting emotions, instincts and drives is a premise common both to Nietzsche, whom Strindberg admired, and Freud, whom he anticipated. 


\section{S. Jain}

\section{References}

Bollas, C. (2000). Hysteria. London: Routledge.

Freud, S. (1919). A Child is Being Beaten. In Collected Papers II, London: Hogarth Press.

Freud, S. (1950). Totem and Taboo. (J. Strachey, Trans.) Abingdon: Routledge. (Original work published 1913)

Greenway, J. L. (1968). Strindberg and Suggestion in Miss Julie. South Atlantic Review, 51(2), pp. 21-34. Irigaray, L. (1985). This Sex Which Is Not One. (C. Porter, Trans.). Ithaca, NY: Cornell University Press. Klein, M. (1986). The Selected Melanie Klein. J. Mitchell (Ed.). Harmondsworth: Penguin. pp. 176-200. Lacan, J. (1979). The Four Fundamental Concepts of Psycho-analysis. London: Penguin.

Mitchell, J. (1999). Mad Men and Medusas. London: Penguin.

Sprinchorn, E. (1968). Strindberg and the greater naturalism. Tulane Drama Review, XIII, 119-129. Strindberg, A. (1992). Miss Julie. (H. Cooper, Trans.) London: Methuen. (Original work published 1888) Templeton, A. (1990). Miss Julie as "A Naturalistic Tragedy". Theatre Journal (Baltimore), 42(4), 468-480. 